\title{
28 Research Square \\ Genetically engineered wheat releases insect pheromones to ward off pests
}

\author{
Toby J.A. Bruce \\ Gudbjorg I. Aradottir \\ Lesley E. Smart \\ Janet L. Martin \\ John C. Caulfield \\ Angela Doherty \\ Caroline A. Sparks \\ Christine M. Woodcock \\ Michael A. Birkett \\ Johnathan A. Napier \\ Huw D. Jones \\ John A. Pickett
}

\section{Video Abstract}

Keywords: pest control, genetically engineered, crop plant, wheat

Posted Date: February 27th, 2021

DOI: https://doi.org/10.21203/rs.3.rs-279892/v1

License: (c) (i) This work is licensed under a Creative Commons Attribution 4.0 International License.

Read Full License 


\section{Abstract}

The aphid -- one of the most common crop pests in the world - has a weakness that scientists have now learned to exploit. When attacked by predators, the bugs release a pheromone to tell fellow insects to scatter. Biologists have proposed spraying these alarm pheromones directly on crops to prevent pest damage, but synthesis is costly. With the advent of genetic engineering, though, the cheaper option is to modify crops to produce the deterrents themselves. In 2015, biologists at Rothamsted Research, an agricultural research station in the UK, reported the first engineering feat of this kind in wheat. To make wheat release insect pheromones, the group inserted a gene from the peppermint plant, which allows plants to produce the appropriate chemical. Then, they tested whether the altered plants' volatile compounds were capable of repelling the pests. Using a multi-chambered olfactometer to provide different odor options, the scientists looked at how much time three types of aphids spent in each environment. All three species spent far more time away from the areas with the aroma of the engineered wheat, suggesting the modification successfully acted as a deterrent. Similarly, when scientists placed a small drop of the alarm pheromone made by the engineered plants on aphid colonies already feeding on regular wheat, most of the bugs dispersed. The pheromone has the added benefit of attracting aphid enemies, such as parasitic wasps. And indeed, the researchers found that compared to controls, wasps spent more time hanging around and foraging on the engineered plants before flying away. Finally, the team tested the new plants in the field, growing plots of wheat and counting the numbers of aphids and wasps through several seasons. Unfortunately, the results observed in the lab were not repeated in the field - the pheromone-releasing plants harbored populations of aphids and beneficial insects the same size as those on regular wheat. The results indicate that while this type of engineering is capable of producing pheromones that ward off pests, more work will be necessary to make sure they protect crops in real-world conditions. Nevertheless, once successful, the concept might also be employed to control insects that spread diseases to farm animals and people. 